\title{
The Development of International Programs in a School Of Social Work
}

\section{Frank B. Raymond}

\begin{abstract}
During the last decade increasing numbers of schools of social work have adopted an international mission and have developed a variety of activities to reflect their global perspective. In earlier years, however, relatively few schools expressed a global mission, offered coursework on international social work, provided field placements or other opportunities to expose students to international learning, or extended components of their academic programs to other countries. An early leader in doing such things was the College of Social Work at the University of South Carolina (COSW), where the author was privileged to serve as dean for 22 years (1980-2002) when many of these developments occurred. This paper will discuss how this school acquired an international mission and developed various programs to manifest this commitment. The paper will describe, in particular, the college's signature achievement in international social work education - the development and implementation of a Koreabased MSW program. The COSW was the first school of social work in the US to offer a master's degree in its entirety in a foreign country. It is hoped that the recounting of this school's experiences will offer guidance to other social work education programs that are exploring ways of expanding their international initiatives.
\end{abstract}

Keywords: International social work, international education, globalization, social work education, academic partnerships, study-abroad

The various international activities that have taken place at the COSW over the past 25 years have occurred in response to the changing world situation and the consequent need for students to be educated appropriately for service in this new world order. The first part of this paper will therefore discuss these global changes and their implications for social work practice and social work education.

\section{The Need for a Contemporary Global Perspective and Mission}

During the past several decades the world has experienced several social changes that have been radical, drastic and far-reaching. These major social changes have impacted every nation, altering their culture, economy, and socio-political institutions. They have required paradigm shifts, or a re-ordering of the constellation of concepts, values, perceptions and practices that form society's vision of reality. These changes are best understood as transformational changes in the sense of metamorphosis, whereby an organism (like a butterfly) becomes something new, remarkable and dramatic; in such changes the organism has not been replaced, but has evolved from one state to another.

Throughout earlier periods of history radical social changes occurred less often, took longer to unfold, and were sometimes confined to nations or continents. However, during the past 20-30 years several social changes have taken place that have affected the entire world and they have transpired rapidly. These transformational events have included

Frank B. Raymond, Ph.D., LICSW, ACSW, is Dean Emeritus and Distinguished Professor Emeritus at the College of

Social Work, University of South Carolina, in Columbia, SC.

Copyright (C) 2014 Advances in Social Work Vol. 15 No. 1 (Spring 2014), 143-162 
climate change, globalization, innovations in technology, and developments in biomedical sciences and health care. Raymond $(2011,2013)$ has described how these four changes have had major impacts on challenges, roles and practices of professional social work in the United States and in other countries.

In order for social workers to practice successfully in light of these major social changes they must have a global perspective. All social workers - from those who practice in small US rural communities to those who work in NGOs in other countries are personally and professionally affected by these radical global changes. The clients they serve are also impacted by these changes. Social workers must therefore embrace a relevant world-view paradigm in order to engage in appropriate and effective practice at either the micro or macro level. This global perspective requires that social workers move beyond a parochial local, regional, or even national perspective and to understand that their clients are directly affected by what happens in other parts of the world. It is essential that social workers understand that "the world is flat" (Friedman, 2005) and that the lives of all people throughout the world are interconnected in a multiplicity of ways. Events in other nations such as war, economic crises, trade agreements, population movements, and climate changes influence the lives of people in all countries and have implications for their social service needs.

Beyond understanding social work practice from such a global perspective, the radical social changes that have occurred require social workers to adopt a more global mission. The world is now our "service area," and increasing numbers of social workers will practice abroad in coming years. It is important for the field of social work to have such a world vision of practice. Global developments have resulted in the growing need for micro-level and macro-level social workers to serve in more countries, to work with new client populations, to provide new types of services, and to respond to the emergence of new problem areas. There are many types of assistance social workers can provide to help improve the overall health and well being of people in other nations. Now, more than ever, the social work profession has a critical role to perform in helping those who are in need around the world, and this should be a commitment of our field.

The Millennium Development Goals, which were unanimously adopted by all of the 191 member states of the United Nations in 2000, help frame the global needs that social work should be concerned with during the coming years (United Nations, 2010). These goals, which the UN committed to achieving by 2015, are as follows:

1. to eradicate extreme poverty and hunger;

2. to achieve universal primary education;

3. to promote gender equality and empower women;

4. to reduce child mortality;

5. to improve maternal health;

6. to combat HIV/AIDS, malaria, and other diseases;

7. to ensure environmental sustainability; and

8. to develop a global partnership for development.

There are numerous jobs that professional social workers can perform in their efforts to achieve objectives such as those set forth in the Millennium Development Goals. 
These include, among other roles, serving as advocates, community organizers, policy developers, organization administrators, lobbyists, social development experts, relief agents, crisis intervention experts, therapists and counselors. As the need for social work services continues to grow globally, the various types of professional roles for social workers also continue to increase. Obviously many of these new roles will require that social workers possess special sets of knowledge, values and skills. The social work profession has never before offered so many possibilities for service, both in the US and abroad. Indeed, the Bureau of Labor Statistics (2010-11) has projected that in the US, alone, the field of social work will be one of the growing areas of employment in coming years.

\section{The Need to Prepare Students for Practice in a Changing Global Environment}

The provision of appropriate and effective social work services to respond to problems and needs that have resulted from radical world changes obviously demands social workers who are adequately prepared for these new roles (See Link \& Ramanathan, 2010; Pawar \& Cox, 2010). All schools of social work must rise to the challenge of educating students to respond to the new client needs of the $21^{\text {st }}$ century. This means that social work educators must have a clear understanding of major changes that are occurring in the world and their impact on social work. It also means that schools should prepare all students to provide services in a global, interconnected society - to engage in what is often referred to today as "international social work."

In earlier years, international social work was seen by some writers as a discrete area of social work practice, and by others as programs of social work with an international focus (including those carried out by intergovernmental agencies or by non-governmental agencies). Today, however, the term "international social work" is used increasingly to describe social work practice within the context of globalization. Healy and Link (2011), in their comprehensive handbook of international social work, also reflect this broader viewpoint. Their position is that today's social workers necessarily work with service users and colleagues from diverse cultures and countries, and that they therefore need to operate within an expanded worldview. They also contend that globally relevant concepts such as human rights, development, and inclusion offer new perspectives to enhance one's understanding of policy and practice. Their book, which contains an extensive collection of content by authors from throughout the world, demonstrates the integral and necessary nature of international social work knowledge to all areas of practice, policy, and research. This conception of international social work from a broader perspective suggests that all schools of social work must prepare students for practice in a changing global environment.

The Council on Social Work Education (CSWE), the accrediting body for social work education programs in the US, now mandates the inclusion of international content in the curriculum. CSWE has signaled its intent to do more to promote a global perspective in social work education. It is noteworthy that the theme of the organization's Annual Program Meeting in Dallas, Texas in Fall 2013, was "Global Social Work-The 
World Is Here." Clearly CSWE is advocating for schools to see the "big picture" of global social work and prepare students for practice within this new paradigm. CSWE has also provided guidance to schools to assist them in developing such programs. CSWE's Commission on Global Social Work Education developed a white paper on this topic that was adopted by CSWE as its official policy statement on international social work education (Council on Social Work Education, 2008). This document describes, among other things, the history of international social work education; the goals, knowledge base, values and beliefs of this approach; the primary educational models used; and important curricular issues. The paper also provides an extensive listing of resources for schools of social work to utilize in developing international education programs.

It is now incumbent upon schools of social work in the US to follow the recommendations and guidance of CSWE and develop programs that will equip their students with a global vision and with the knowledge, values and skills needed to practice effectively in an interconnected and rapidly changing world. More and more schools are meeting this challenge, although to varying degrees. It is encouraging that increasing numbers of schools of social work are incorporating a global component into their mission statements. These include urban and rural schools, small and large programs, public and private institutions, secular and church-related schools, and programs at all levels of social work education. Many schools also reflect their global missions in their statements of their program rationale, goals and objectives. In addition, more schools are designing or redesigning their curricula so that their educational programs will better accomplish their global purposes. These curricula usually integrate content on social work in a global environment into various courses. Furthermore, the curricula of a great many schools include specifically designed course offerings that focus on different aspects of global social work. Regardless of how a school implements its international curriculum, the focus should be on imparting to students the knowledge, values and skills for practice in a world that is becoming increasingly global.

As schools endeavor to develop globally-related programs, they must do so within the context of major changes that are occurring in the world environment. Examining the impact of current social changes can provide a frame of reference that will lead schools to focus on a variety of other topics that are critical to developing an international perspective - teaching students an understanding of immigration issues; developing in students appropriate attitudes towards diversity; preparing students for services to newlyemerging population groups; equipping students to meet the changing needs of traditional population groups that are expanding; developing in students the knowledge and skills to engage in social advocacy on behalf of specific populations; preparing students to engage in social development; etc.

No doubt there are a number of frameworks schools can use to build a curriculum around the context of current social changes. Raymond $(2011,2013)$ has described one model whereby schools can develop curriculum content around four themes: the impact of technology, globalization, climate change, and advances in bio-science and health care on the practice of social work. 
Many schools have not only included international content in the classroom curriculum, but have also done other things to help students develop a global perspective and acquire knowledge and skills to engage in practice within an interconnected world. These activities include, for example, offering international field placements, providing study-abroad opportunities for students, arranging international student exchanges, providing international faculty exchanges, developing partnerships with foreign academic institutions, and offering online courses collaboratively with faculty and students in other countries. Such activities are effective means of extending a school's global mission. Cross-cultural programs, in particular, can be valuable because of the mutual benefits they provide to parties in the participating countries.

\section{One School's Experience in Developing International Programs}

The College of Social Work at the University of South Carolina was an early leader in developing international activities to address new and developing needs resulting from global development, to equip students for practice in an increasingly interdependent world, and to provide current practitioners with learning experiences that will enable them to provide better services in a global environment. Given the other competing demands of social work education, the COSW did not make sweeping programmatic changes overnight. Rather, in response to developing educational needs and opportunities, the college gradually created a number of activities aimed at meeting its larger global objective. (It should be noted that the college did these things within the context of the broader university's mission statement, which included an international component.) These activities are described below.

\section{Curriculum Content}

Since the early 1980s the College of Social Work has offered curriculum content on international social work. The COSW began by making a concerted effort to incorporate international content into a number of its normally-required courses, both as substantive content and as illustrative material. In addition to including such content within existing courses, for over thirty years the college has offered specific courses that have a significant focus on international subjects. For example, the COSW developed an undergraduate course, titled Social Work in Other Nations. This course examines social welfare systems in selected nations of the world and focuses, in particular, on variations in services. At the graduate level, the COSW created a course titled Seminar on Social Work Education and Human Services in Another Nation. During this course students examine the differences and similarities between the human service system of another country and that of the United States. Each student selects a specific area of study consistent with his or her field of practice interests and analyzes this area in depth. Both of these courses are sometimes taught in conjunction with a study-abroad experience offered to students during Maymester or Summer School (see below). In these instances, the coursework also entails travel to and within another nation, and includes visits to social agencies in other nations, visits to human service agencies, and occasionally attendance at an international conference in the other nation that is visited. The COSW also provides independent study options to those graduate students who wish to pursue 
in-depth study of particular international topics. The college's doctoral students can also focus their dissertation study on international subjects.

There is a growing body of literature to help schools develop international curriculum content. In addition to the writings of earlier scholars in this area, there have been a number of significant recent contributions to the literature by distinguished academicians such as Lynne Healy, Brij Mohan, James Midgley, Richard Estes, Michael Sherraden, Manohar Pawar, David Cox, Rosemary Link, Chathapuram Ramanathan and others. Furthermore, there are several important journals devoted to international social work such as Social Development Issues, Journal of Comparative Social Welfare, International Social Work, and International Journal of Social Welfare. In addition, through its Katherine A. Kendall Institute, the Council on Social Work Education (2013) maintains an extensive database of curriculum resources. All these materials can provide important resources to schools of social work as they expand their international course content.

\section{Study-Abroad Program}

In 1985 the College of Social Work created a program aimed at providing studyabroad opportunities for students and current social work practitioners. This college was one of the first schools of social work to offer study-abroad learning experiences. The COSW's study-abroad program has included visits to numerous countries, including Mexico, Israel, Greece, England, Scotland, France, Russia, Sweden, India, Ghana, Ireland, and Brazil.

Students who engage in these learning experiences do so under the direction of one of the COSW professors, and they earn course credit for their work. They are required to do advance study about the country to be visited, to attend lectures and presentations by educators and agency officials in the host country, to gather data while on the trip (often focused on a selected topic of study), and to meet usual course requirements such as the preparation of papers.

From the beginning of this program the COSW's study-abroad trips have been offered not only to students from the University of South Carolina, but also to students from throughout the US. These students can receive course credit either from the University of South Carolina or from the students' respective home institutions (depending on the regulations of their universities).

In addition to students, social work practitioners are also invited to participate in the study-abroad trips. These participants are awarded continuing education credits after meeting appropriate COSW and university requirements. These trips have made it possible for participants to become familiar with social problems and needs in other countries and to learn about social work and human services in other nations. It is believed that these study-abroad experiences make the practitioners more culturally sensitive and equip them with new knowledge that enables them to provide more effective services to their clients in the US.

Although relatively few schools of social work offered study-abroad courses in earlier years, such programs are now widespread in social work education. Given this 
plethora of study-abroad opportunities provided by schools of social work, the Council on Social Work Education (2013) maintains a listing of study-abroad programs currently offered.

Given the growth of study-abroad programs in recent years, the CSWE has also established guidelines for all types of academic programs that involve study in other countries including academic courses abroad, field practicums abroad, international service learning projects, internships abroad, independent learning abroad, and group study abroad (Council on Social Work Education, 2012). CSWE's Council on Global Learning, Research, and Practice, one of the councils under the CSWE Commission on Global Social Work Education, created these guidelines for establishing international programs for social work students that meet not only the CSWE Educational Policy and Accreditation Standards but also the Global Standards for the Education and Training of the Social Work Profession established by the International Association of Schools of Social Work and the International Federation of Social Workers. Therefore, these general Study Abroad Guidelines are offered for social work programs to use in planning international study opportunities for their students. Any school that wishes to establish a study-abroad program would be well advised to follow these guidelines from the beginning of the planning process.

\section{International Partnerships}

In 1988 the COSW began developing partnership arrangements with academic programs and human service organizations in other countries. Eventually the College established as many as twenty international partnerships in countries including, for example, Mexico, Germany, South Korea, India, and China. These partnerships have had significant positive impact on COSW and the other institutions involved. Healy (1986) has described how international partnerships enable educators to work collaboratively to build knowledge and relationships which contribute to global solutions to common concerns, and to prepare students to live and work in a world in which cross-cultural understanding and cooperation are considered essential.

Despite of the potential benefits of international partnerships, however, the process of developing such collaborative arrangements can be challenging. In another article this author has described many of the issues involved in creating international partnerships (Raymond, 1998). In that article Raymond discusses the importance of developing and demonstrating cultural awareness throughout the collaborative process, especially in the early stages of a new relationship. In fostering the personal relationship with a potential partner, one should move slowly in exploring the possibilities for collaboration in order to develop understanding and trust. The success in achieving formal institutional agreements will be built upon the foundation of the personal relationship between the primary collaborators.

Raymond (1998) also discussed the process of developing the formal written contract between the collaborating institutions, emphasizing the importance of establishing expectations that are realistic, insuring that all key actors are in agreement, and obtaining approvals at all appropriate levels within each institution. Most universities that engage in 
international partnerships have well-developed procedures for developing formal agreements, such as those of Princeton University (Princeton, 2013).

There are a number of potential barriers to developing successful international partnerships. These barriers include costs involved, language and cultural differences, bureaucratic differences regarding things such as methods of instruction or transfer of academic credits, and problems that may arise in arranging for visas, transportation or living facilities (Raymond, 1998). In addition to these barriers, perhaps a more serious area of concern in developing international academic partnerships is the historical tendency of schools to export ideas, methods and goals from one country to another without sufficient regard for their relevance to societies whose needs, problems, laws and values are significantly different (Cetingok \& Hirayama, 1990; Hartman, 1990). Avoiding, or at least mitigating, such problems and barriers can best be achieved when those persons who are trying to establish an international partnership have an understanding and genuine respect for each other's cultures, traditions, and academic systems. It is therefore helpful when each partner already has a familiarity with the other person's culture. Otherwise, it is wise to devote preparatory time towards learning about the other culture in order to develop the knowledge and attitudes required for a successful partnership.

The COSW has developed formal agreements, or memorandums of understanding, with all of its international partners, clearly describing the expectations for each of the participants. These partnerships have resulted in a numerous activities, including faculty exchanges, student exchanges, curriculum sharing, cross-cultural research, and joint service projects. Many faculty members from these partner institutions have come to the University of South Carolina as visiting scholars, and a number of faculty from the COSW have spent sabbaticals or shorter periods of time for research or study at the partner institutions.

The COSW has also hosted numerous student groups from its partner institutions. These groups are normally led by professors from their respective universities. The COSW assists in arranging lodging and local transportation for the visiting groups. During the visits the COSW provides lectures to the visitors and arranges for them to visit human service agencies in South Carolina in order to learn about the delivery of social work services in this country.

As a result of COSW's partnerships, many students from other countries have enrolled in the college's MSW Program. These partnerships have also led to the enrollment of several students from other countries in the college's Ph.D. program. Reciprocally, a number of COSW students have had field placements in countries of the partners, and some have taken courses at the host institutions.

\section{International Conferences}

As part of its commitment to fostering international collaboration and exchange in the field of social work education and practice, the COSW has hosted or sponsored a variety of international conferences and symposia. For example, in 2001, the COSW hosted the annual meeting of Human Services Information Technology Applications 
(HUSITA). HUSITA is an international professional association that promotes the ethical and effective use of information technology to serve humanity. The organization, which was created in 1983, focuses on the development of knowledge and the transfer of technology within human services. HUSITA meets at locations throughout the world to bring together social work educators and practitioners as well as professionals from other areas of human services. (For more information on HUSITA, visit www.husita.org.)

In 2004, the COSW and one of its partner schools in Korea, Kangnam University, co-sponsored a conference in South Korea. This meeting, with the theme of "Social Welfare Issues and Social Worker's New Roles in the Era of Globalization," brought together social work educators and practitioners from countries throughout the world.

The COSW also served as a sponsor of two international meetings of the International Consortium for Social Development-ICSD (formerly known as the Inter-University Consortium for International Social Development). ICSD is an international organization that is concerned with empowering people to bring about economic and social improvement in their lives. It is comprised of scholars, practitioners and students from social work and other disciplines from throughout the world. In 2003 the COSW, under the leadership of one of its faculty members, Dr. Goutham Menon, sponsored and planned the organization's $13^{\text {th }}$ biennial meeting which was held in India. In 2005, the COSW sponsored and planned ICSD's $14^{\text {th }}$ biennial meeting that was held in Brazil, and a faculty member, Dr. Julie Miller-Cribbs, chaired this effort. In both instances, local schools of social work served as hosts and co-sponsors of the meetings. In addition, the author of this paper served as President of ICSD and, in that role was involved in the planning of the 2007 biennial conference, held in Hangzhou, China (and co-sponsored by the COSW), and the 2009 conference, held in Monterrey, Mexico.

The COSW's leadership in international conferences has served to support its other international initiatives. For example, many people have learned about the COSW's global mission through participation in its conferences. This international attention has led to enrollment of students from other countries in the COSW's academic programs, expanded participation in the COSW's study-abroad programs, fostered the creation of partnerships with academic institutions in other countries, and led to the development of a variety of exchanges and collaborative ventures among COSW faculty and conference participants from other countries.

\section{MSW Program in Korea}

One of the most notable achievements of the COSW in advancing international social work was the establishment of a branch program in South Korea to offer the school's MSW program in that country.

\section{Responding to a Need}

In 1992 the Korean Association of Social Workers (KASW), representing the South Korean social work community, contacted the dean of the COSW through a mutual friend, Dr. Paul Kim. Dr. Kim is a Korean-American social work educator who, at that time, was on the faculty at another university in the US. Knowing of the COSW's 
demonstrated commitment to international social work, KASW inquired about the possibility of the COSW's establishing a master's degree program in South Korea. (Social work education in Korea is not comparable to that in the US. It is structured differently than in this country, and is primarily an academic discipline with less focus on practice training.) The KASW representatives said that although many Koreans desired a master's degree in social work from the United States, most of them could not come to this country to study. They were precluded from doing so because of the cost involved, their life circumstances, and their inability to speak English. KASW asserted that the COSW would make an important contribution to the field of social work in Korea if it would offer its MSW program there, with courses taught in the Korean language (Raymond, 1997).

\section{Obtaining Approval}

Korean representatives came to South Carolina to meet with the dean and faculty. They described social work and social work education in Korea, explained the educational needs and life circumstances of potential students, and discussed various options for offering a degree program in Korea. After learning about these needs and opportunities, the faculty gave the dean approval to move forward in developing a plan to offer the MSW degree program in Korea. Planning began in spring 1992. The dean, along with Dr. Paul Kim, visited Korea to assess needs, opportunities, and resources that might be available to mount such a program. These visits entailed meeting with potential students, going to various academic institutions with whom the COSW might partner in the venture, locating possible housing for faculty, assessing available resources such as libraries and technology, meeting with officials of agencies that might be supportive of the program and its students, etc.

In response to the needs and circumstances of the Korea social work community, and based on resources of the COSW, the dean developed a formal proposal for an off-site MSW program in Seoul, Korea. He presented this proposal to the faculty and they granted their approval of the plan. The faculty also authorized the dean to submit the proposal to the appropriate authorities. (Different written versions of the plan were required to meet the guidelines of these various authorities. The fundamental elements of the plan were identical in each version.)

Because the program was to be conducted at an off-site location, with all classes being offered in Korea, prior approval by the CSWE Commission on Accreditation was required. A proposal was developed under the Commission's Evaluative Standard 7: Alternative Programs. This standard stated the following.

7.0 Alternative programs introduce change into one or more components of a program already accredited by the Commission. If such alterations do not constitute substantive changes the program must, as part of the self-study process at the time of submitting materials for accreditation, include information about the alternative program and its evaluation results.

7.1 An alternative program that offers the equivalent of one or more academic years of the social work degree program, whether the class or field curriculum or 
both, in an off-campus location must submit a proposal to the Commission on Accreditation for approval before implementing the program.

The COSW had been offering a part-time program in South Carolina for many years. This program included options for both block and concurrent field placements. The COSW proposed to offer this same program on site in Seoul, Korea. The intent was that the Korea-based MSW program would be in all ways comparable to the South Carolinabased program, with the only differences being the location, the timing of the courses, the waiver of TOEFL scores for applicants to the program, and the inclusion of interpreters to translate the faculty lectures from English to Korean.

The plan for the alternative Korea-based MSW program was submitted to the CSWE Commission on Accreditation in December 1992, and it was approved by the Commission in January 1993. During this same time period the plan for extending the college's MSW program to Korea was submitted to, and approved by, various levels of authority within the University of South Carolina. Following ultimate approval by the university's board of trustees, the proposal was submitted to the South Carolina Commission on Higher Education, and that state agency also gave its approval to the plan.

While approval of the plan was being sought in the US, it was also necessary to obtain approval in Korea. After the dean's visits to a number of universities in Korea that offered social work education programs, the COSW extended an offer to Kangnam University to serve as a partner in this venture. (Kangnam University was well-known for its reputation of having the oldest, largest and most prestigious undergraduate program in Korea). The president and other officials at Kangnam University accepted the COSW offer, and the proposal was then submitted to the South Korea Ministry of Education. Because of Korea's previous experiences with a number of bogus foreign academic programs, the Ministry of Education was initially somewhat wary of the COSW proposal. Consequently, in addition to submitting the proposal to the Ministry, it was necessary for the dean to meet personally with officials from that government agency to provide reassurance of the legitimacy of the proposed program. The COSW's partnership with Kangnam University, given its reputation as a highly respected university in Korea, also provided credibility to the proposal. The Ministry of Education gave its approval to the plan and steps were then taken to implement it.

Following approval at the various levels in the US and Korea, the COSW began to implement the plan. This included hiring Dr. Paul Kim to be the director of the program (additional Korean-American faculty were later hired by the COSW). Courses were scheduled and faculty were assigned to teach them. Classroom space was set up in Korea and resources such as library materials and technology equipment were sent to Seoul. The COSW began to accept applications and to process them through its admissions office and the university graduate school.

An initial class of 28 students was admitted to the Korea-based MSW program. The COSW began offering courses to this first cohort of students in summer of 1993. With the initiation of this program, the College of Social Work at the University of South 
Carolina became the first school of social work in the US to offer its master's degree program in its entirety in a foreign country.

At first the program was offered only in collaboration with Kangnam University, but after the program began several additional Korean universities joined the partnership. These have included Dan Kook University, Hallym University, Induk Institute of Technology, Korea Christian University, Chang Shin College, Sookmyung Women's University, Seowon University, and Suwon University. The participation of these other schools not only provided further enhancement to the credibility and reputation of the MSW program, but also brought to bear additional resources such as classrooms, libraries and technology. Kangnam University has remained the primary partner, however.

\section{Structure of the Program}

The Korean program is structured on the framework of the part-time MSW program that the COSW has offered in South Carolina for many years. Faculty from the University of South Carolina travel to Korea to teach courses on-site during the summer and in specially arranged schedules during the fall and spring semesters. As in the parttime program in South Carolina, courses are taught during evenings and weekends in order to accommodate the needs of working students. All faculty members who teach in Korea participate in an orientation program prior to going abroad in order to heighten their cultural sensitivity and make them more effective educators in Korea. In addition to the regular classroom teachers, Korean-American professors from the COSW's faculty serve as interpreters in each class. These interpreters, who hold master's and doctoral degrees in social work from United States schools and are familiar with social work and human services in both the US and Korea, help ensure the correct meaning, cultural relevance, and appropriate application of the course content. (Their roles might best be described as "co-teaching.") These Korean faculty members not only serve as interpreters, but they also teach some courses themselves. When they teach, of course, they do not require additional translators.

Applicants to the Korea-based program must meet the same admission requirements as persons who apply for enrolment in the South Carolina-based MSW program, with the exception of submitting passing TOEFL scores as normally required of foreign students. Their applications must be submitted in English in order to be reviewed by the COSW's admissions office and the university's graduate school. In addition to the Korean students, each cohort includes 3-4 American students that are affiliated with the US military stationed in Korea (either soldiers, military employees, or spouses). This arrangement not only meets the needs of these English-speaking students, but it contributes significantly academic value. This enables all students to experience greater diversity, and the students learn much from each other's personal and professional backgrounds.

The block field placement plan is used in the Korean Program. This follows the same model used with COSW's part-time program in South Carolina. Students must complete all of their foundation courses before they can begin their first year field placements. The first year field placements are offered during Fall Semester of the students' second year 
of matriculation. The advanced year field placements occur after all other advanced year courses have been completed, except for the final integrative seminar, or capstone course. This course is offered simultaneous with the second year field placements during the fall semester of the students' last year of enrollment.

The field instruction program is carried out in the same manner as in South Carolina. The field director selects agencies and field instructors who meet the COSW's usual criteria. Most of the Korean field instructors are graduates of the Korea-Based MSW Program, with the exception of a few social workers who are affiliated with the US military in Korea. The field director not only sets up the placements in Korea, but also returns to Korea to participate in the evaluation of the students' learning at the end of the field placement experience. The field director is assisted in these efforts by a Korea-based social worker who received her MSW degree in an earlier class that matriculated in the Korea-Based MSW Program. Having lived in the United States previously, she speaks fluent English. She serves as the field director's translator during visits, stays in touch with the students and the field instructors while field placements are taking place, and keeps the field director informed as to what is happening.

The total Korea-based MSW program requires 2.5 years to complete. Students come to the Columbia campus for graduation (this is not required, but most of them strongly want to do so - often bringing family members with them). Because it would strain the COSW's resources to attempt to offer courses to both foundation and advanced students simultaneously in Korea, the college does not begin to offer classes to a new cohort of students until the preceding one has graduated. After a group graduates from the program in December, another class begins its studies the following summer.

The Korea-based program is completely self-supporting from student tuition. The university does not charge its normal tuition and fees and no state funding is contributed towards the costs of the program. Instead, based on projected costs, a budget is established before each cohort of student begins study and the students pay for these costs on a pro-rated basis over their 2.5 years of study.

\section{Evaluation of the Program}

Because the Korea-based MSW program was developed as an alternative program under the CSWE accreditation guidelines, it was necessary to evaluate the effectiveness of the undertaking. Evaluation of the program was also required by the South Carolina Commission on Higher Education.

In order to provide assurance of the program's adherence to accreditation standards, the COSW invited CSWE's Director of the Division of Standards and Accreditation to visit the program in Korea on two occasions for review and feedback purposes. The reviews of the Director were extremely positive and her advice was very helpful to the college in insuring the quality of the program and its compliance with accreditation standards.

In order to provide further assurance that the program was of high quality and was meeting accreditation requirements, in the early years of the program the COSW 
contracted with two separate outside evaluators with expertise in social work education, including accreditation standards, to provide independent reviews of the program. These evaluators visited the program in Korea, met with officials from Kangnam University, attended classes, interviewed students, interviewed field instructors, examined course materials and students' performance records, and met with the faculty in Columbia.

The findings of these external evaluation activities provided additional independent assurance that the alternative program was, in all relevant aspects, equal in quality to the Columbia-based program. Specifically, the findings revealed that:

- The program was carefully planned and was administered/managed well.

- Students were well qualified and highly motivated, and many opportunities were available and used to foster connections among students and between students and faculty.

- Students performed better overall on comparable classroom assignments than did similar students in the Columbia program, and most received A's or B's in all their coursework.

- Student field performance was equivalent to performance of similar students in the Columbia program.

- Faculty were very positive about the program and students unanimously rated faculty highly.

- The learning and educational support services (e.g., buildings, technology, library holdings) available to students were at least adequate.

- Most limitations of the program were related to environmental conditions (e.g., heat, travel time, resources, isolation of faculty).

- Initially learning resources were seen as a problem, but the COSW addressed this by developing a supplemental library and utilizing the libraries of more partner institutions.

- In summary, the Korea program was found to be highly commensurate with the part-time MSW program in Columbia in all areas, including curriculum content, texts and other materials, instruction methods, evaluation methods, and student outcomes.

In the year 2000 the COSW went through its regular review for reaffirmation of accreditation and the Korea-based program was part of that review. The above data from outside evaluations were included in the college's self-study document. The Koreanbased program evaluation plan for the reaffirmation review also included many of the same measures that were used to evaluate the Columbia-based program. Specifically, these included:

- Student grades

- Field Instructor's Evaluation of Students 
- Teaching Evaluations

- Field Work Rating Form

- Field Liaison Assessment

The 2000 reaffirmation review resulted in unconditional approval of the COSW's master's degree program, including the Korea-based component. The regular review of the COSW's accreditation occurred again in 2008 and, once again, the review resulted in unconditional reaffirmation of accreditation. This reaffirmation of the college's accreditation during its last two reviews by the Commission on accreditation has thus provided solid evidence that students in the Korea-based program have parallel course content, similar resources and learning opportunities (libraries, equipment, field placements), and a program of equivalent quality to the Columbia-based MSW.

The Korea-based program has also been evaluated by the Southern Association of Colleges (SACS) as part of its accreditation of the University of South Carolina. This organization has also given its approval to the Korea-based initiative as an integral part of the COSW's master of social work degree program.

Since the COSW began offering courses to the first cohort on students in 1993, six groups of students have graduated. With the graduation of the current cohort in December 2013, over 175 students will have received their MSW degrees through the Korean program.

Most graduates of the Korea-based MSW program have moved into positions of increased responsibility as a result of their graduate degrees. Over 50 are now teaching social work education courses as full-time faculty (20) or adjunct faculty (30) in Korean Universities. A large number of graduates have been promoted to high ranks within their organizations and some have assumed leadership positions in other institutions, including the Korean government (one is now Korea's Senior Secretary to the President for Employment and Welfare). Over a dozen of the alumni have gone on to pursue doctoral study in social work education programs in Korea and in the United States. (Two of the alumni have completed Ph.D. degrees at the University of South Carolina.)

Faculty from the University of South Carolina have enjoyed the experience of teaching abroad, and have found that they are better social work educators as a result of insights they acquired from living, studying, and teaching in another country. Similarly, faculty from Korean universities who participate in the program have emphasized that they profit from this cross-cultural activity. Several faculty from both countries have engaged in joint research projects which have resulted in scholarly publications and papers presented at national and international conferences.

\section{Conclusion}

The College of Social Work at the University of South Carolina was not the first school of social work to engage in international activities, nor does it claim to be preeminent in this arena. Other schools have a long history of offering study-abroad courses, providing international field placements, conducting research or developing 
special projects in other countries, offering educational content to academic institutions abroad, and so on. However, there were relatively few schools involved in such activities thirty years ago. Starting with its international coursework and its study-abroad courses, the COSW was an early entrant in this field. The COSW gradually expanded its activities to include a variety of internationally-focused projects. With the implementation of its Korea-based MSW program, which represented a unique venture among schools of social work, the COSW established what might be considered a leadership position among schools. In this age of globalization more and more schools of social work are endeavoring to develop international initiatives of various types. It is hoped that the above recounting of the experiences of the COSW can be of benefit to schools seeking to expand their efforts in the global field.

There are several lessons to be learned from the COSW's experiences in developing international activities. One of the most striking conclusions is that the establishment of an international program of any type has widespread effects that extend beyond the immediate objective of that initiative. Often there are benefits of international activities far greater than those imagined by the planners. For example, a study-abroad course provides much more than an exposure of students to another culture and a different system of social services. As Johnson, Johnson, and Good (1995) pointed out, students who have participated in international studies return with noticeable growth in selfconfidence, general maturity, adaptability and responsibility, as well as international awareness and an understanding and appreciation for another culture. These authors also noted that faculty members who engage in international projects seem to attain greater vision and credibility, and to emerge as leaders as a result of the challenges they have faced in international settings.

There is no doubt that faculty members from the COSW have become better teachers as a result of their engaging in study-abroad courses, teaching international content, becoming involved in the college's partnerships with schools in other countries, participating in international conferences, and teaching in the Korea-based MSW program. Faculty report that these international experiences have served to broaden their world views, increase their sensitivity to other cultures, and expand their repertoire of options for enriching the curriculum. The overall professional development of the COSW faculty as a result of their international experiences support what other writers have found. For example, Sanders (1980) explained that engagement in multicultural experiences enhances one's flexibility, psychological adaptability, and capacity to make shifts in one's frame of reference. Similarly, Harris (1990) pointed out that developing understanding of differences between oneself and others, as well as points of unity, can help one look again at what was previously believed and to see new possibilities.

Another lesson from the COSW's experiences is that engagement with partners from other countries is inevitably a two-way experience - and it should be. A number of writers (Hartman, 1990; Healy, 1986; Healy \& Link, 2011) have emphasized that recognition of mutuality and sharing, in contrast to an attitude of noblesse oblige, is essential for international collaboration. Faculty and students who have participated in the COSW's study-abroad courses, international conferences, or the Korea-based program have soon learned that we have much to learn from other countries. Indeed, some of the 
human service systems of other countries are far superior to those of the US and offer models for replication.

As a school of social work embarks of an international endeavor it is essential that the leader(s) of the effort be passionate about it. It is not unusual for a school to include an international component in its mission statement, but in order to effectuate that mission there must be a strong commitment to the importance of some specific goals and objectives. This kind of enthusiasm for a proposed international enterprise will lead one to look for opportunities for action.

The next lesson from the COSW's experiences builds on the preceding discussion. That is, one must be aware of opportunities when they arise and quick to embrace them. For example, the COSW's first study-abroad trip grew out of the availability of a university-owned property in Mexico that the university's president encouraged deans to use for academic purposes. The HUSITA international conference took place because that organization, which meets biennially in different countries, was looking for an institution in the US that could host the event. The Korea-based MSW program resulted from an invitation from the Korean social work community to offer a degree in that country.

Another lesson for schools that are interested in developing international programs is the importance of networking with others who are engaged in the global arena. Indeed, many of the initiatives developed over the years at the COSW were generated by the examples of work done at other schools. It is helpful for faculty who want to develop international activities to go to sessions having that focus when attending national conferences such as the CSWE Annual Program Meeting. It is also useful for them to participate in international social work organizations including the International Association of Schools of Social Work (IASSW), the International Federation of Social Workers (IFSW), the International Consortium for Social Development (ICSD), and the International Council on Social Welfare (ICSW). These organizations provide forums for educators, researchers, students, and practitioners to come together to hear expert speakers, present papers on their own work, share ideas, and learn from each other in regard to international social work education and practice. These types of organizations also offer a variety of other resources to facilitate international collaboration and development such as publications, web-based information, and opportunities for online communication and data exchange among members.

Another lesson from the experience of the COSW is that it is essential to obtain support for the proposed venture from leaders at every possible level. It was necessary for the COSW to obtain the endorsement and approval of many authorities in developing the Korea-based program, so efforts were made to assure these parties of the legitimacy and value of the initiative. For example, it was helpful to have the CSWE Director of the Division of Standards and Accreditation visit the program, not just to have her provide guidance regarding accreditation standards, but also to give her the opportunity to see the worth of the program. Similarly, the provost of the University of South Carolina visited the Korean program and he became one of the strongest advocates of the endeavor within the university and with the South Carolina Commission on Higher Education. In Korea, 
also, the dean cultivated the friendship of officials within Kangnam University and at the Ministry of Education. Their support helped facilitate the approval processes in that country and has helped maintain the ongoing success of the program.

It is also important to insure the availability of sufficient resources in order for an international project to succeed. This requires being knowledgeable of potential funding sources, such as private and governmental grants. Also, it is sometimes necessary to risk capital expenditures at the front end of a venture in order to develop the potential project. The COSW had to commit resources in order to create study-abroad courses, mount international conferences, and make the necessary foreign trips to develop the Korean program. Sufficient human resources are also necessary for any foreign endeavor. Offering successful study-abroad trips requires faculty with the requisite knowledge and skills. Hosting international conferences calls for faculty with the necessary subject area knowledge as well as planning and management abilities. Offering academic programs in other countries requires faculty that have not only the needed knowledge base, but also the desire and willingness to work abroad. (Sometimes it is necessary to hire faculty with international backgrounds and fluency in another language, as was the case with COSW's Korea-based program.)

Finally, engagement in international endeavors requires full commitment on the part of the school. This means a willingness to commit the necessary money, human resources, and time to insure the success of the project. It is therefore absolutely essential to obtain the support of the school official(s) who have the authority to make such commitments, as well as pledges of full participation from all persons who will be involved. Sometimes long-term financial commitments are not possible, particularly when there is no guarantee of the success of the project. In any case, there should be a clear, written plan for the project that includes goals and objectives, a time frame, a description of the roles of each actor, an evaluation scheme with intermediate measures of progress, and a projection of future efforts that includes contingency plans. As discussed above under the section on "international partnerships," when organizations from other countries are involved there should be formal agreements between the institutions in the respective countries that spell out the roles, responsibilities, and expectations of all parties.

It should be evident from this paper that the involvement of a school of social work in any type of international activity should not be entered into lightly - but thoughtfully, earnestly and resolutely. No doubt this level of engagement will seem frightening and overwhelming to some faculty and administrators. However, we are living in times of transformational social change and it is incumbent upon schools of social work to maintain relevancy in light of these events. Schools must expand their institutional worldviews. Schools must equip their students with the appropriate knowledge, skills and values to practice effectively in our fast-changing environment. And, to be pertinent in a shrinking world, schools of social work would do well to consider developing concrete programs that will involve students and faculty in international activities. As the College of Social Work at the University of South Carolina has learned through its experiences with international programs, the benefits of engaging in such projects are profound and rewarding. 


\section{References}

Bureau of Labor Statistics. (2010-11). Occupational outlook, 2010-11 edition. (BLS Bulletin 2800). Washington, DC: U.S. Government Printing Office.

Cetingok, M., \& Hirayama, H. (1990). Foreign students in social work schools: Their characteristics and assessment of programmes in the US. International Social Work, 33, 243-253.

Council on Social Work Education. (2008). United States-based conceptualization of international social work education. (White Paper prepared for the Global Commission on International Education of the Council of Social Work Education (CSWE). Retrieved from http://www.cswe.org/File.aspx?id=31429

Council on Social Work Education. (2012). Study abroad guidelines for social work. (Developed by the CSWE Council on Global Learning, Research, and Practice). Retrieved from http://www.cswe.org/CentersInitiatives/KAKI/50754/56061.aspx

Council on Social Work Education. (2013). Social work study abroad programs. (A listing prepared and maintained by the Katherine A. Kendall Institute for International Social Work Education of the Council on Social Work Education.) Retrieved from http://www.cswe.org/CentersInitiatives/KAKI/KAKIResources/StudyAbroad.aspx

Council on Social Work Education. (2013). Katherine A. Kendall Institute resources. (A database prepared and maintained by the Katherine A. Kendall Institute for International Social Work Education of the Council on Social Work Education.) Retrieved from http://www.cswe.org/CentersInitiatives/KAKI/KAKIResources.aspx

Friedman, T. L. (2005). The world is flat: A brief history of the twenty-first century. New York, NY: Farrar, Straus \& Giroux.

Harris, R. (1990). Beyond rhetoric: A challenge for international social work. International Social Work, 33, 203-213.

Hartman, A. (1990). Our global village. Social Work, 35, 291-292.

Healy, L. M. (1986). The international dimension in social work in social work education: Current efforts, future challenges. International Social Work, 29, 135-147.

Healy, L. M., \& Link, R. J. (Eds.). (2011). Handbook of international social work: Human rights, development, and the global profession. New York, NY: Oxford University Press.

Johnson, W. L., Johnson, A. M., \& Good, J. L. (1995). Planning international university programs. International Education, 25, 31-38.

Link, R. J., \& Ramanathan, C. S. (2010). Human behavior in a just world: Reaching for common ground. New York, NY: Rowman \& Littlefield.

Pawar, M. S., \& Cox, D. R. (Eds.). (2010). Social development: Critical themes and perspectives. New York, NY: Routledge. 
Princeton University. (2013). International Princeton: Research + Partnerships. Retrieved from https:/www.princeton.edu/international/partnerships/linkages/partnership-guidelines/

Raymond, F. B. (1997). Preparing social workers to assume human service needs in the Korean Peninsula: An example of cross-cultural exchange. Journal of Global Awareness, 300-305.

Raymond, F. B. (1998). Developing international education partnerships. Journal of Global Awareness, 334-341.

Raymond, F. B. (2011). Current revolutionary changes and their implications for Christians in social work. Social Work and Christianity, 38(1), 1-28.

Raymond, F. B. (2013). The future outlook of social work in the United States. Paper presented at the International Social Work Forum, Korea Association of Social Workers, Seoul, Korea.

Sanders, D. S. (1980). Multiculturalism: Implications for social work. International Social Work, 23, 9-16.

United Nations. (2010). Millennium Development Goals Report 2010. Brussels, BE: Author.

\section{Author note}

Address correspondence to: Frank B. Raymond, Ph.D., 133 Dibble Lane, Columbia, SC 29223. Email: frankr@mailbox.sc.edu

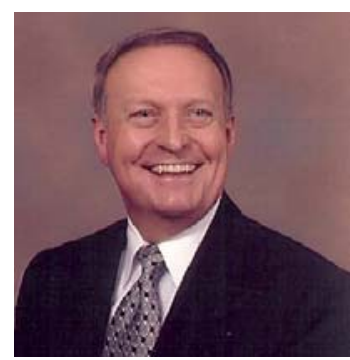

Frank B. Raymond is Dean Emeritus and Distinguished Professor Emeritus at the College of Social Work at the University of South Carolina. He joined the faculty of the College of Social Work at the University of South Carolina in 1972, and served as Dean of this college from 1980 until his retirement in 2002. He has published five books related to administration, technology and social work education, as well as over 200 book chapters and journal articles in areas such as organizational management, program evaluation, social work education, technology in higher education, and international social work. 